\title{
Features of Service Members' Adaptation to Civilian Life: Legal Aspects
}

\author{
Mykola Inshyn ${ }^{1, *}$, Vasyl Bontlab ${ }^{2}$, Volodymyr Sokolov $^{3}$, Serhiy Boyko ${ }^{4}$ and Kateryna Inozemtseva ${ }^{5}$ \\ ${ }^{1}$ Department of Labor and Social Security Law, Taras Shevchenko National University of Kyiv, Kyiv, Ukraine \\ ${ }^{2}$ Department of Constitutional, Administrative and Economic Law of the Faculty of Law, Academy of Labour, \\ Social Relations and Tourism, Kyiv, Ukraine \\ ${ }^{3} J u d g e$ in Supreme Court, Kyiv, Ukraine \\ ${ }^{4}$ Doctor of Law, Director of BigData YuEY Independent Rating Agency, Kyiv, Ukraine \\ ${ }^{5}$ Department of Administrative Commercial Law and Financial and Economic Security, Sumy State University, \\ Kharkiv, Ukraine
}

\begin{abstract}
The purpose of the study is to analyze the regulatory and legal support for the adaptation of service members to civilian life in the United States, France, and Germany to identify elements that could be useful for implementation in Ukrainian legislation. The 5 stages of adaptation that each service member goes through after completing his/her service when returning to civilian life are identified and analyzed. It is found that all analyzed countries begin the adaptation process several months (or years) before the end of service. In addition, former service members consistently receive financial assistance. The obtained results can be used by scientists for further analysis of regulatory and legal support and, on its basis, direct implementation of procedures for adaptation of service members to civilian life.
\end{abstract}

Keywords: Adaptation, contract military service, enforced conscription, service member, social security.

\section{INTRODUCTION}

During military service, a person's subjective views on public relations change dramatically due to the peculiarities of such service. Military service has an impact on psychological and moral condition of a person, which, in turn, leads to some differences in views on different life situations. For service members who leave their service, which has already been identified with their "home", the return to civilian life is sharply opposed to the controlled way of life in military units (Herman and Yarwood 2014). After completing their service, former service members consider themselves physically and mentally stable, so they do not retire, but start another career (Walker 2013) in order to lead an active life, share experiences with others, but as a result, they experience significant cultural and social changes in their life.

The essence of social adaptation of service members to the conditions of civilian life is manifested in the following stages: training, entry, adaptation and development (Terziev 2018). Moreover, each service member undergoes the following "types" of adaptation:

- $\quad$ psychological - which is aimed at mastering the values and culture that exist in a civilian

*Address correspondence to this author at the Dragomanova, 1G, Kiev, 02068, Ukraine; Tel: 380993133233; E-mail: inshynmyk1@ukr.net environment (McAllister, Callaghan, and Fellin 2018);

- legal - which is aimed at mastering the rules governing the social and legal status of a person discharged from military service, his/her rights, and responsibilities;

- $\quad$ professional (social) - which is aimed at social support and plays the role of an additional resource for a former service member, who faces life challenges (Setiasih and Jayanti 2018).

Adaptation is considered successful if a service member has accepted new living conditions and continues to search for work that would provide material living conditions for him/her and his/her family. The problem is that in practice, reserve officers have serious difficulty finding new jobs (Terziev and Dimitrova 2014a).

Many service members, after being discharged from the army, start committing crimes of various kinds (MacManus and Wessely 2011), think about suicide and commit it, become physically incapable (Wilmoth, London, and Parker 2011), mentally ill, engage in domestic violence (Booth-Kewley et al. 2013). For example, the results of the National Vietnam Veterans Readjustment Study (NVVRS) showed a high rate of divorce, unemployment, and accidents, among which road accidents - $49 \%$, suicide - $65 \%$ (Busuttil 2010). As 
of 2005 , suicide rates among service members (who were serving or quitted at that time) increased sharply from 10.3 to 11.3 per 100,000 people, and in 2008 to 16.3 per 100,000 people (LeardMann et al. 2013). As of 2009, about 300 service members committed suicide, with the military mortality rate exceeding the civilian mortality rate (Burns and Mahalik 2011).

The crimes committed by the former service members are violent and sexual crimes (Treadwell 2016). The annual report of the Scottish Prison Service showed that after the First World War from 1918 to 1920 , the level of crimes committed by ex-service members increased proportionally from 20 to 80 and only from 1920 to 1924 , they began to decrease gradually (McKay 2019).

The procedure of service members' adaptation after the end of service is envisaged at international and national levels (Nukusheva et al. 2020). In particular, at the international level, there are programs funded by the North Atlantic Treaty Organization (NATO), for instance, "Partnership for Peace" (Moore 2012). There is also the International Foundation for Social Adaptation, the Charitable Organization "Transformation of service members", etc. Another program - "Social adaptation of discharged military personnel" - is funded by the Organization for Security and Co-operation in Europe (OSCE) (Bagmet and Kabaieva 2016).

At the national level, there are programs adopted by public authorities. For example, in Ukraine, it is the Order of the Cabinet of Ministers of Ukraine "On the State target program of social and professional adaptation of service members that are subject to discharge and persons discharged from military service for the period up to 2017" (Cabinet of Ministers of Ukraine 2013). In the United States, for example, there is The Comprehensive Soldier Fitness Program (Steenkamp, Nash, and Litz 2013).

However, the process of adaptation without the implementation of targeted programs at the national or international levels eliminates the possibility to regulate the process. Targeted programs and legal regulation of service members' adaptation are important since a service member can directly get acquainted with his/her rights and responsibilities as well as study and determine the most, in his/her opinion, productive "way" of adaptation in case of existence of several possible.

Service members' adaptation is a complex process of interaction of the latter with specialists in medicine, sociology and psychology, whose actions contribute to the process of re-socialization of a service member to new, somewhat different realities of life, as stress or trauma causes a number of psychiatric disorders, especially depressive and anxiety states (Jon et al. 2011). The idea that a person must cope with stress on one's own without any outside help has lost its relevance long ago, so now treatments focus on understanding and compassion, rather than on the shame and punishment that used to be inherent in military culture (Keats 2010). At the same time, the untimely consideration of the social base for service members' adaptation can have a negative impact not only on society as a whole but also on the families of service members (Terziev 2018). Failure to adapt leads to domestic violence. This happened in the family of John Gagan, who after military service, unable to find work, systematically abused his wife (McKay 2019).

In addition, as a result of the rigidity of military service, behavior only within the statute, as well as due to their own characteristics, service members often think about suicide during the period of adaptation (Mehdiyev 2013). Returning home after military service can be not only a relief but also a difficult period in the life of a service member, despite the fact that each of them is happy to return home (Adler 2011).

Dialectical Behavioral Therapy (DBT) is aimed at combating suicidal ideation - based on evidence that has shown its effectiveness in reducing suicidal ideation (Kliem, Kroger, and Kosfelder 2010). The existence of DBT includes weekly individual psychotherapy sessions, group skills training and telephone conversations with a coach to prevent suicide (Koerner, Dimeff, and Swenson 2007). Such classes are conducted since the mental treatment is not used enough, despite efforts to increase its availability. For example, among veterans returning from Iraq or Afghanistan, 25-30\% indicated concerns about their own mental health. However, after analysis, it was found that $23-40 \%$ met the real criteria for some mental disorders (Denckla et al. 2015).

In the United States, service members have the right to adapt within 180 days before their transfer to reserve or retirement, and this right does not depend on years of service (Military Handbooks 2016). In the United Kingdom, France, Germany and other developed countries, there is also a practice of preparing discharged service members for civilian life before they leave The Armed Forces (Terziev and Dimitrova 2014a). 
It is clear that without a properly formed regulatory framework, the adaptation process will be in question. It is implied that despite the existence of national and international targeted programs of social and professional adaptation of service members, such programs do not provide a direct sequence of actions to be performed by specialists concerning service members' adaptation. On the contrary, such programs indicate only the bodies of state or local selfgovernment that should be engaged in such adaptation or create conditions for its implementation. Therefore, the development of the sequence of service members' adaptation is entirely up to the above-mentioned bodies. The topic of service members' adaptation to civilian life in accordance with the requirements of personnel policy in the Armed Forces of Ukraine is one of the least studied in Ukrainian military science (Horbenko et al. 2013).

In view of this, the purpose of this article is to determine the legal aspects of service members' adaptation to civilian life. To achieve this goal, it has been decided to analyze international legislation, which determines the legal status and the procedure of service members' adaptation (within regulations) after their service. Practical recommendations have been developed on the necessary legal regulation of service members' adaptation.

Based on this goal, the main objectives of this study are as follows:

- characterizing the general aspects of the experience of social protection and social adaptation of service members discharged in reserve in the practice of foreign countries;

- $\quad$ singling out features of legal regulation of service members' adaptation;

- establishing a list of elements that could be implemented in national legislation.

\section{MATERIALS AND METHODS}

In the process of working on the research, scientific methods were used, which became the basis for a comprehensive analysis of the following:

- $\quad$ legal support;

- $\quad$ a set of rights and freedoms of service members at the end of service; return to civilian life, as a result of the application to service members of the adaptation procedure practiced in different countries of the world.

An analysis of international practice in the field of regulatory support for the adaptation of service members was conducted. The following legal acts were analyzed in the work:

- regulations that establish and indicate the features of social adaptation (including military) in the world as a whole (European Convention on Social and Medical Assistance and its Protocol (ETS No. 14), European Convention on Social Security (ETS No. 78));

- regulations of some countries (Title 10 "Armed Forces" of United States Code; In Germany - the Federal Law "On Conscription", "On the legal status of Bundeswehr service members", "On the status of service members"; In France - the Law on the Status of Military Service Members, Code of Conscription);

- legal acts of Ukraine regulating the same social relations (On social and legal protection of service members and their families: Law of Ukraine No. 2011-XII as amended on 20 Mar 2020; Order of the Cabinet of Ministers of Ukraine "On the State target program of social and professional adaptation of service members that are subject to discharge and persons discharged from military service for the period up to 2017 ").

The analysis of these regulations in their systematic relationship and comparison allowed achieving the results of this study.

In addition, the scientific works of international scientists were analyzed, which indicated the peculiarities of the adaptation of ex-service members (Adler 2011; Denckla et al. 2015; Jon et al. 2011; Terziev and Dimitrova 2014a).

The legal acts of Ukraine that establish the peculiarities of adaptation in Ukraine, and the scientific research that describes the peculiarities of adaptation in other countries, have been analyzed and correlated (Horbenko, Khoma, and Shpanchuk 2014; Husak 2008; Razov 2013).

It is found that all analyzed scientific works concern adaptation of service members who serve under the 
contract, thus ignoring the necessity of carrying out adaptation of military conscripts that still exist in Norway, Estonia, Denmark, and Ukraine (Kasearu and Olsson 2019).

A comparison of existing doctrines, views, and principles of legal regulation was made. Features were identified that, in the future, could be used to update the legislation of Ukraine in the field of social security of service members, including the issue of mandatory social adaptation at the end of their service. The research of doctrinal and comparative law allowed identifying, analyzing and summarizing the features inherent in the normative aspects of service members' adaptation to civilian life.

Throughout the article, qualitative research methods are used, which mainly consist of descriptive research, as the purpose of the article, among other things, is to characterize the general aspects of the experience of service members' adaptation in the practice of foreign countries.

\section{RESULTS}

The policy of ensuring service members' adaptation to civilian life after discharge from military service (or retirement) is an important part of the activities of every country in the world as the worldview of people who have served under contract (as in most countries of the world e.g. Britain, Israel, etc. is changing. If in the $X X$ century the issue related to the effective management of the transition of former servicemen from military to civilian life was not given special attention, then there is no doubt that in the XXI century the issue should become one of the priorities for modern democratic states (Bulmer and Eichler 2017).

Therefore, as they return to civilian life, ex-service members may experience discomfort due to the lack of, for example, rules of conduct that they have followed throughout their service or daily routine and other normal (for them) things. The problem is exacerbated if ex-service members have personally participated in military operations, as such a factor always has a negative effect on even the most psychologically resilient and stable person.

Veterans, who are often seen as exemplary citizens, can create political problems for the state elite, as their disagreement with officials on public policymaking can seriously undermine the credibility of government. One of the most striking examples in world history of the 2nd half of XX century is when American veterans of the Vietnam War were able to mobilize significant support for their anti-war campaigns through their role as former comrades (Bulmer and Eichler 2017). Upon the whole, research into the transition from military to civilian life speaks of so deeply affected by psychological influences that the word "transition" seems both a standard expression and a concept automatically used when discussing the topic of transition from military to civilian life. However, the concept of transition can include both explicit problems (e.g. financial problems, finding a job, moving to a new area, loss of a social network) (Tsindeliani 2019), and subtle problems (e.g. biological, social, psychological, religious / spiritual) which military personnel are facing during their transition from a military context to a civilian one (Grimell 2019).

Former military personnel may feel constrained or abandoned, or even as if they are living in a state of oblivion after leaving their military communities and military comrades. Civil societies may have little or no interest, at least through the eyes of veterans, in full recognition and recognition of former military personnel for the sacrifices they made in the line of duty (Grimell 2019).

On the professional side, the results of many studies clearly show that it is difficult for civilian employers to interpret the military skill set into specific job specialties (Bush and Middlewood 2013; G. Johnson and W. Johnson 2000). As a result, both employers and retired military personnel increase the likelihood of job dissatisfaction and, ultimately, staff turnover. This is primarily due to the fact that negative or positive perceptions of work are the result of the employee's emotional point of view, employment conditions, job expectations, and connection to work. In other words, a veteran employee's perception of overqualification is associated with intentions to quit one's job as they negatively influence job satisfaction. The feeling of underemployment directly affects the veteran's attitude to work, his health (both physical and mental), labor productivity, absenteeism and, ultimately, staff turnover (Dexter 2020).

Of importance is a sufficient regulatory framework that would cover all possible problematic situations in the process of service members' adaptation to civilian life after service. Otherwise, the lack of a normative document that would regulate the adaptation procedure at the national or international level leads to the consequences outlined in Figure 1. 


\section{Lack of normatively defined procedure for service members' adaptation to civilian life}

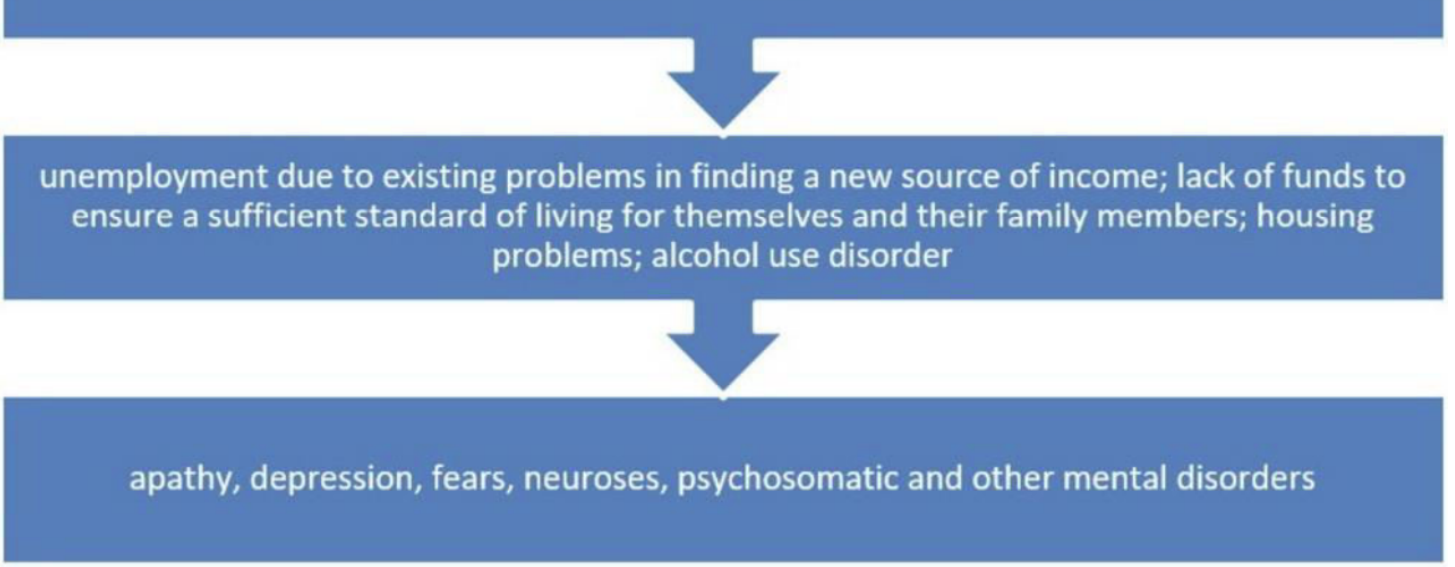

Figure 1: Consequences of the lack of sufficient regulatory support for the procedure of service members' adaptation to civilian life.

Among the international regulatory support for service members' adaptation to civilian life, the following regulations can be identified:

- $\quad$ Universal Declaration of Human Rights;

- International Covenant on Civil and Political Rights;

- International Covenant on Economic, Social and Cultural Rights;

- $\quad$ Convention for the Protection of Human Rights and Fundamental Freedoms.

The Constitutional Law also contains a norm stating that the honor and dignity of every person, as well as his or her security, are recognized and guaranteed as the highest value of the state. The state also provides social protection for persons serving in the Armed Forces, other military formations and members of their families.

Among the sectoral legislation on state social protection of service members, there are some regulations in which the level of service members' social protection (their adaptation to civilian life after service) differs depending on the country, continent, customs, traditions, and the prevailing legal system. Such regulations, in particular, are in Germany Federal law "On conscription", "On the legal status of Bundeswehr service members", "On the status of service members", "On the pension of civil servants"; in France, the Law on the Status of Service Members and the Code of Conscription.
The problem with ensuring service members' adaptation is the fact that such adaptation is provided mainly for service members under contract, i.e. for those who have voluntarily agreed to serve in the military on personal grounds or as a result of the inability to find any other job. In addition, in the vast majority of countries around the world, military service under contract is a normal phenomenon (USA, UK, France) after the waiver of conscription (Figure 2).

All the factors listed in Figure $\mathbf{2}$ could be called common, however, some were specific to each country and became the main reasons for the abandonment of conscription and transition to contract military service. Thus, today, the contract is considered in many countries around the world as another type of work with the payment of wages and full social security during and after service.

Currently, the adaptation process to civilian life is mainly established for service members who have served on a contract basis. At the same time, for conscripts, such a procedure is either not provided for or is the same as for contract soldiers. This is a problem from the standpoint that contract soldiers for a long time have been in the same conditions dictated by the statute of the military unit and the requirements of sectoral legislation. Such requirements and rules have become part of their normal rhythm of life. It is stressful for contract soldiers to return to civilian life after military service, which is not the case with conscripts. The latter often enter the military unit against their will and are under constant stress in the process of service. However, the process of returning to civilian life, as well 


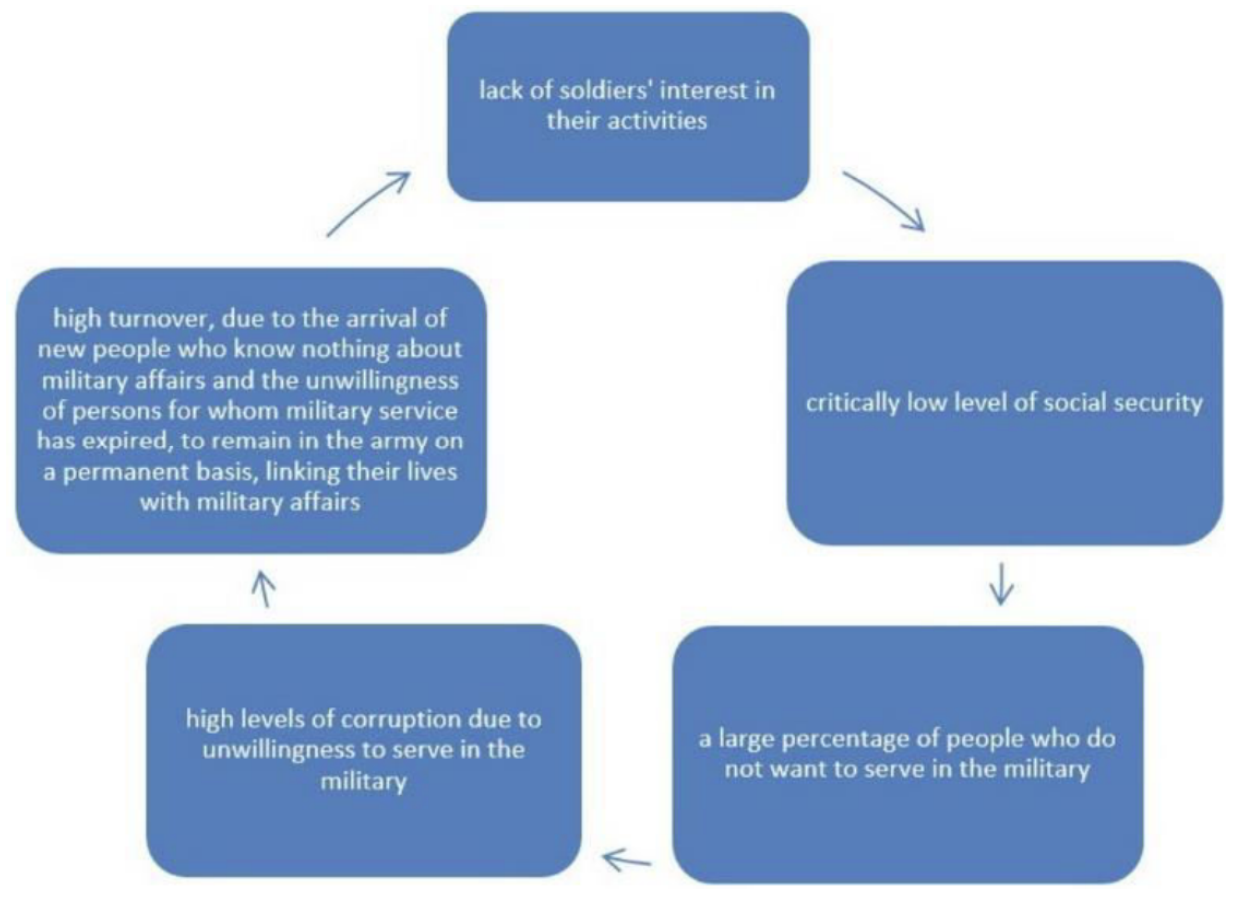

Figure 2: The facts that became the main reasons for the refusal of states from military service.

as that of contract soldiers, requires an adaptation process. For a short period of time during which such persons serve in the military (in some countries it is 18 months, in others -12), they must quickly get used to the new rules provided by the statute, and after the service, immediately return to "normal" civilian life. This can be an even bigger problem for them than for contract soldiers.

Given that contract military service is, among other things, the main type of income of citizens and other people in some countries, it has been necessary to establish the legal framework for the following:

- $\quad$ grounds and procedure for hiring;

- features of dismissal or decision to terminate work at will;

- $\quad$ pay;

- $\quad$ social security of the service members and their families.

It should be noted that the same legal requirements should exist for the establishment of a clear procedure for service members' adaptation to civilian life.

The process of service members' adaptation always takes place in 5 stages:

preparatory stage;
- $\quad$ stage of psychological stress before discharge;

- $\quad$ stage of acute mental reactions at the entrance to civilian life;

- $\quad$ stage of acute mental reactions before leaving the military;

- $\quad$ stage of revising old stereotypes and acquiring the missing ones (Terziev and Dimitrova 2014b).

At each of these stages, it is important to "accompany" the former service member in order to "accept" the situation that has arisen.

Thus, the most important thing is to provide support during the first two stages. Support can be provided as follows:

- conducting a complete analysis of the personality, mental state of the person, his/her level of stability and susceptibility to various mental illnesses. Then, in case the person:

- $\quad$ shows high stability in critical situations, it should be enough for him/her to have a single interview with a psychologist for a real awareness of the fact of military service completion and the need to return to civilian life.

- $\quad$ is characterized by a low level of mental stability in critical situations, which, inter alia, is 
confirmed by various documented facts (violations of the rules of conduct; frequent conflicts with other service members, etc.) - It is needed to conduct frequent conversations with psychologists, and doctors; conduct additional observations outside the "office" of the psychologist, and provide more active assistance in their adaptation;

- assistance in the development of an "adaptation" plan, which will include consultations on the possibility of future employment in non-military affairs;

- active cooperation between the department responsible for social security of service members and employers who would be willing to create or provide new jobs to persons who have completed military service;

- $\quad$ providing opportunities for former service members to receive education (including higher education), by providing them with grants to pay for training, or by providing the opportunity to combine service and training.

It is important that those who have helped a former service member in the initial stages should keep in touch with him/her in all subsequent stages. Here one can draw a parallel with coaching psychologists who teach, help, listen to ex-service members, their problems, and help to overcome psychological problems that may exist in connection with the end of military service.

Provision at the legislative level for the procedure of service members' adaptation to the conditions of civilian life after the end of service is important for:

- $\quad$ maintaining a high level of social security for service members;

- maintaining the mental health of ex-service members;

- assisting in their ability to ensure a normal standard of living for themselves and their family members after service.

\section{DISCUSSION}

The system of social adaptation and integration of ex-service members abroad is developing dynamically and is characterized by various features (Ivashchenko 2016), which include benefits, such as granting "temporary" status (housing) (USA), assistance in receiving education (Germany, Great Britain).

Germany was the first to point out the importance of social protection and developed a system of state protection for veterans (especially the disabled) after the First World War. Veterans, and especially the disabled, were granted pensions due to disability; for people with a severe form of disability, the pension was approaching the level of the salary of a qualified specialist. The Law on Severe Disability enshrined a rule that employers had to hire and allocate only for people with disabilities. By 1914, about half of the war invalids had received counseling or retraining. Later, such a system was borrowed by other countries (Zorictueva 2010).

Motivation and social adaptation are not in the last place in the social policy of the military department. In this area, actions are aimed at implementing projects and programs on motivation, qualification and retraining, employment, and starting one's own business. This approach satisfies the desire for selfimprovement of those service members who have to retire or otherwise leave the army and prepare for civilian life (Terziev 2016)

A distinction should be made between adaptation procedures for retired service members and those transferred to the reserve. Because, for the former, adaptation in the form of getting a new job will not be a goal, but a "bonus" after service (due to the opportunity to continue working), while for the latter - getting a new job is the basis of future well-being (Chertushkina 2013)

The analysis of service members' adaptation to civilian life in some countries of the world has led to the following conclusions. Some countries around the world contribute to adaptation by:

- $\quad$ retraining service members for new professions (Germany);

- $\quad$ paying tuition fees;

- $\quad$ assistance in finding a job, for example, by establishing contact with employers who are willing to provide ex-service members with vacancies (UK).

In addition, the organization of military training in the UK provides professional adaptation to living conditions (Korytkov 2019). 
In the United States, the United Kingdom, and France, the process of adaptation begins long before a person's release to best prepare the person for the future challenges of society (Horbenko et al. 2014).

In the United States, the content of social protection and adaptation includes a set of specially designed programs to meet the social needs of retired service members, their pensions and housing, organization and conduct of leisure, providing necessary assistance to their families, as well as psychological and professional adaptation (Razov 2013). The social adaptation of service members is considered successful if all members of a service member's family are effectively integrated into the civilian living conditions, and not its individual members. Although it remains clear that the adaptation of an ex-service member's family depends on him/herself and his/her own adaptation process (Razov 2015).

The issue of service members' social adaptation needs a comprehensive approach and close relationship of public, military and governmental organizations (Gordeev 2018). That is why the issues of service members' adaptation are mainly dealt by the Ministry of Defense, however, in some cases, an additional body is created, which performs auxiliary functions to organize and directly promote adaptation (USA, France, Germany). In France, the existing state and public organizations are aimed at adaptation. These organizations include, in particular: the department "Mission of Professional Mobility", structural units created in each headquarters of the military forces; department of professional reorientation and conversion of service members (Razov 2014).

In the United States, Britain, France, and Germany, there is a financial payment to ex-service members. This payment may be of different purposes, but it is mainly to facilitate training in order to further establish oneself in the labor market and get a job that can provide a stable income and therefore a decent standard of living for a former service member and his/her family members (Husak 2008). The readiness for a normal life and professional self-realization of former service members is limited by problems related to their professional qualification, which does not correspond to civilian specialties. Moreover, the modern labor market needs professionals, and employers prefer young professionals (Kosharnaya and Chalykh 2017).

In addition to sectoral regulations in NATO member countries, special attention is paid to the adaptation of service members to civilian life after service. Because the system of social protection in such countries involves not only the implementation of general provisions provided for in international and national legislation but also the creation of organizations whose activities are aimed at solving problems of social protection. The leadership of NATO member countries believes that one will join the army only when one feels care, respect and the possibility of self-realization during the service and in the future.

The process of adaptation of service members' families also seems to be important, as its success largely depends on a number of objective and subjective conditions, social experience, life attitudes, and so on (Kulumbegova 2018). In most parts of the world, considerable attention is also given to the adaptation of service member's family, given that in the contractual form of service, the latter was often dependent on a commander who could redirect the service member, and therefore his/her entire family, from one place to another. At the same time, for most countries of the world (including those discussed above), a contractual form of military service is typical in which future service members actually decide to sign a contract. Thus, contract military service is in fact a job for which two agree: an employee (future service member) and an employer (represented by the Ministry of Defense).

There are countries in which military service is still not a right but a duty, such as Norway, Estonia, Denmark and Ukraine. In Denmark, all 18-year-old men are required to be conscripts, but due to the large percentage of volunteers, the actual number of conscripts is around 1-4\%. In Estonia, too, a third of conscripts are volunteers (Kasearu and Olsson 2019). In this case, enforced conscription is considered, which is mandatory for a certain category of citizens when they reach a certain age, and for a certain period of time (term).

The studies discussed above relate mainly to the regulation of service members' adaptation in the contract service. Such studies generally lack the depth of research on the issue of service members' adaptation to civilian life. In the issue of conscript military service, much attention is paid only to adaptation directly to military service by a person who has not been previously associated with it (Mukhametzhanov et al. 2013), however, avoiding the issue of adaptation to civilian life after the statutory period of service. 
In addition, programs of service members' development and adaptation at the national level do not assist the latter in preparing for civilian life. At the same time, the factor of state coercion in the form of liability for improperly conducted adaptation procedures is not established.

The results of the study emphasize the importance of strategic approaches and corresponding strategic (program) documents in the adaptation of former military personnel to civilian life. In order to effectively ensure the adaptation of servicemen to civilian life, in particular in the labor market, it is advisable to develop and approve a state target program for social servicemen released from reserve. It should provide, first of all, the development of theoretical and legal bases for its operation, as well as respond to existing challenges and threats, and provide the necessary organizational measures. The establishment of a working group (or other advisory body) to develop proposals for methodological approaches to the development of such a program would help to solve the problems. At the same time, it should be noted that ensuring the competitiveness of retired servicemen on the labor market is not possible without appropriate comprehensive adaptation of the representatives of this socio-demographic group, which will be based on the established complex system of state, public and international institutions.

As for the restrictions on the adaptation of foreign experience in organizing legal support for the adaptation of military personnel in relation to Ukraine, it should be noted that there are no objective obstacles in this direction. This issue is mainly related not so much to the political will or the complexity of legislative procedures, but to the existing situation on the labor market. The analysis of the problems associated with adaptation of retired servicemen to civilian life conditions shows that the process of social adaptation of retired military personnel should be tied to training (retraining) a former serviceman for a specific profession based on regional market demand at his place of work accommodation with compulsory employment. In this context, the latter circumstance can play a very important role.

\section{CONCLUSIONS}

From the analysis of foreign countries' practice in the field of service members' adaptation, it is clear that ex-service members are entitled to the following types of assistance. Namely, psychological assistance - conducting conversations with psychologists on the subject of mastering the values and culture that exist in the civilian environment. Legal assistance - mastering the rules governing the social and legal status of a former service member. Professional (social) assistance - improvement of existing skills, knowledge, abilities, or mastery of new ones and further successful employment.

Such experience is also important for Ukraine because after the end of service, ex-service members either retire immediately (with the payment of pensions in accordance with the law) or independently, without outside help, try to find a source of income and often fail.

Therefore, the practice of organizing legal support for service members' adaptation is important for Ukraine to inform them about their additional, different from others, rights, including the right to adaptation after a military career. The possibility of retraining them is also to be established with tuition fees at public expense. Then conscription will not be necessary for Ukraine because in the case of normal social security, citizens will want to join the military, which will be supported by additional guarantees and rights provided to them by the state.

The problem in the field of service members' adaptation to civilian life is that in most studies of international scholars, the issue of adaptation is considered exclusively in relation to the military who have served in the contract military service. There is a logic in this, as most foreign countries have long since given up conscription. However, in some post-Soviet countries conscription exists today, and there the problem of service members' adaptation either is not considered at all or is considered at the level of declarative norms that establish the fact of possible adaptation but do not establish a direct procedure.

The obtained research results can be used by scientists for further in-depth analysis of the adaptation procedure directly in Ukraine based on international experience, taking into account the fact of greater spread of conscription here. The obtained results can also be used by students of different profiles to deepen their knowledge concerning service members' additional rights after service completion.

The results of the study, which indicate that conscripts sometimes need to adapt more than contract soldiers, are new and can, therefore, be the 
basis for further research. In addition, the results obtained can be used to improve the legislation of those countries in the world where conscription is still practiced.

\section{REFERENCES}

Adler, Amy B. 2011. "The psychology of transition: Adapting to home after deployment." Pp. 153-174 in Deployment psychology: Evidence-based strategies to promote mental health in the military, edited by Amy B. Adler, Paul D. Bliese, and Carl A. Castro. Washington: American Psychological Association. https://doi.org/10.1037/12300-006

Bagmet, Mykhailo and Alina Kabaieva. 2016. "On the question of the theoretical and methodological basics of attracting students to the Eu-Ukraine association agreement implementation". Public Policy and Economic Development 7:173-183. doi: 10.14746/pped.2016.7.14

Booth-Kewley, Stephanie, Emily A. Schmied, Robyn M. HighfillMcRoy, Gerald E. Larson, Cedric F. Garland, and Lauretta A. Ziajko. 2013. "Predictors of psychiatric disorders in combat veterans". BMC Psychiatry 13:1-11. https://doi.org/10.1186/1471-244X-13-130

Bulmer, Sarah and Maya Eichler. 2017. "Unmaking militarized masculinity: veterans and the project of military-to-civilian transition". Critical Military Studies 3:161-181. https://doi.org/10.1080/23337486.2017.1320055

Burns, M. Shaun and James R. Mahalik. 2011. "Suicide and dominant masculinity norms among current and former United States military servicemen". Professional Psychology: Research and Practice 42:347-353. https://doi.org/10.1037/a0025163

Bush, Tony and David Middlewood. 2013. Leading and managing people in education. Sage.

Busuttil, Walter. 2010. "Combat-related stress". Chapter 12 In Promoting Men's Mental Health, eds. David Conrad and Alan White. Abingdon: Radcliffe Publishing, 2010.

Cabinet of Ministers of Ukraine. 2013. On the State target program of social and professional adaptation of service members that are subject to discharge and persons discharged from military service for the period up to 2017, Order of the Cabinet of Ministers of Ukraine as of 18 Dec 2013 № 1068-r. https://www.kmu.gov.ua/npas/246973104.

Chertushkina, Tatiana. 2013. "The problem of social adaptation of military personnel discharged to the reserve in the training of social workers". Kazan Pedagogical Journal 1:1-7.

Denckla, Christy, Robert Bailey, Christie Jackson, John Tatarakis, and Cory K. Chen. 2015. "A Novel Adaptation of Distress Tolerance Skills Training Among Military Veterans: Outcomes in Suicide-Related Events". Cognitive and Behavioral Practice 22:450-457. https://doi.org/10.1016/j.cbpra.2014.04.001

Dexter, John. 2020. "Human resources challenges of military to civilian employment transitions". Career Development International 25:481-500. https://doi.org/10.1108/CDI-02-2019-0032

Gordeev, Igor. 2018. "Solving the problems of social adaptation of citizens discharged from military service at the regional level (on the example of Kursk region)". Bulletin of the South-West State University 2:62-65.

Grimell, Jan. 2019. "Revisiting Living in Limbo to Illustrate a Pastoral Psychological Understanding of Transition from Military to Civilian Life". Pastoral Psychology 68:93-405. https://doi.org/10.1007/s11089-019-00881-6

Herman, Agatha, and Richard Yarwood. 2014. "From services to civilian: The geographies of veterans' post-military lives". Geoforum 53:41-50.

https://doi.org/10.1016/j.geoforum.2014.02.001
Horbenko, Serhii, Vitalii Khoma, and Genadii Shpanchuk. 2014 "Experience of service members' adaptation to civilian life in the USA". Collection of scientific works of Kharkiv Air Force University 2:42-44.

Horbenko, Serhii, Vitalii Khoma, Genadii, Shpanchuk, and Ivan Smirnov. 2013. "Adaptation of service members to civilian life - one of the main directions of personnel policy development in the Armed Forces of Ukraine". Collection of scientific works of Kharkiv Air Force University 4:15-20.

Husak, Oleh. 2008. "World experience in developing state policy on the formation of professional mobility of service members". State building 1:1-11.

Ivashchenko, Aleksei. 2016. "Social practices of adaptation and integration of dismissed servicemen in Russia and abroad: a comparative analysis". Social and humanities technologies $1: 32-40$.

Johnson, Gloria Jones and Roy W. Johnson. 2000. "Perceived Overqualification and Dimensions of Job Satisfaction: A Longitudinal Analysis". The Journal of Psychology 134:537555. https://doi.org/10.1080/00223980009598235

Jon, Duk-In, Minah Jung, Kang Choi, Eunjung Lee, and Jeong-Ho Seok. 2011. "P.8. a.007 Relationship of military adaptation with early-life stress and resilience in Korean young men". European Neuropsychopharmacology 21:614-615. https://doi.org/10.1016/S0924-977X(11)71005-7

Kasearu Kairi and Ann-Margareth E. Olsson. 2019. "A systemic perspective on children's well-being in military families in different countries". Journal of Military, Veteran and Family Health 5:79-97. https://doi.org/10.3138/jmvfh.2019-0010

Keats, A. Patrice. 2010. "Soldiers Working Internationally: Impacts of Masculinity, Military Culture, and Operational Stress on Cross-cultural Adaptatio". International Journal for the Advancement of Counselling 32:290-303. https://doi.org/10.1007/s10447-010-9107-z

Kliem, Soren, Christoph Kroger and Joachim Kosfelder. 2010 "Dialectical behavior therapy for borderline personality disorder: A meta-analysis using mixed effects modeling". Journal of Consulting and Clinical Psychology 71:936-951. https://doi.org/10.1037/a0021015

Koerner, Kelly, Linda A. Dimeff, and Charles S. Swenson. 2007. "Adopt or adapt? Fidelity matters". Pp. 19-36 in Dialectical behavior therapy in clinical practice: Applications across disorders and settings, edited by Linda Dimeff and Kelly Koerner. New York: Guilford Press.

Korytkov, Vladimir. 2019. "Vocational training of military personnel of the armed forces of the USA, Great Britain and Germany in educational units". Humanities 1:67-73.

Kosharnaya, Galina and Oleg Chalykh. 2017. "Problems of professional adaptation of military pensioners in modern Russian society". Social Sciences. Sociology 4:76-84.

Kulumbegova, Luisa. 2018. "Regional features of the sociopsychological adaptation of military families". Problems of modern pedagogical education 1:322-324.

LeardMann, Cynthia, Teresa M. Powell, Tyler C. Smith, Michael Bell and Besa Smith. 2013. "Risk Factors Associated with Suicide in Current and Former US Military Personnel". Jama 310:496-506. https://doi.org/10.1001/jama.2013.65164

MacManus, Deidre and Simon Wessely. 2011. "Why do some exarmed forces personnel end up in prison?" The British Medical Journal 343:4-5. https://doi.org/10.1136/bmj.d3898

McAllister, Lauren, Jane E. M. Callaghan, and Lisa C. Fellin. 2018. "Masculinities and emotional expression in UK servicemen: “Big boys don't cry?" Journal of Gender Studies 28:257-270. https://doi.org/10.1080/09589236.2018.1429898 
McKay, Cameron. 2019. Ex-Servicemen and Crime in Interwar Scotland. History and Politics eTheses, University of Stirling.

Mehdiyev, Elnur. 2013. "Suicidal attempts among the military servants during the adaptation period". European Psychiatry 28:1. https://doi.org/10.1016/S0924-9338(13)76436-8

Military Handbooks. 2016. 2016 after the Military Handbook. Military Handbooks.

Moore, Rebecca R. 2012. “Lisbon and the Evolution of NATO's New Partnership Policy". Perceptions: Journal of International Affairs 17:55-74

Mukhametzhanov, Amir, Nurlan, Smagulov, Saltanat Zhautikova, Farid Umer, and Karina Zhienbaeva. 2013. "Actual issues of adaptation of military servicemen to military professional activities". Fundamental Research 7:436-439.

Nukusheva, Aigul, Ilyassova, Gulzhazira, Kudryavtseva, Larisa, Shayakhmetova, Zhanna, Jantassova, Amina, and Popova, Larisa. 2020. "Transnational corporations in private international law: do Kazakhstan and Russia have the potential to take the lead?". Entrepreneurship and Sustainability Issues 8(1): 496-512. https://doi.org/10.9770/jesi.2020.8.1(35)

Razov, Pavel. 2013. The essence, structure and content of social protection and social adaptation of servicemen discharged to the reserve (on the example of foreign countries). Army and society 1:3-10.

Razov, Pavel. 2014. "Foreign experience in solving the problems of retraining and employment of military personnel dismissed in the reserve". Power 1:156-160.

Razov, Pavel. 2015. "Risks in the sphere of family life of Russian reserve troops in the context of social adaptation to the conditions of civil life". Historical and socio-educational thought 7:188-193. https://doi.org/10.17748/2075-9908-2015-7-6/1-188-193

Setiasih, Setiasih and Gusti Ayu Putu Mas Jayanti. 2018. "Perceived Social Support and Subjective Well-being of Ex-service People of the Indonesian Defence Forces". Anima Indonesian Psychological Journal 33:190-199. https://doi.org/10.24123/aipj.v33i3.1695

Steenkamp, Maria M., William P. Nash, and Brett T. Litz. 2013. "Post-traumatic stress disorder: Review of the Comprehensive Soldier Fitness program". American Journal of Preventive 44:507-512.

https://doi.org/10.1016/j.amepre.2013.01.013
Terziev, Venelin and Sevdalina Dimitrova. 2014b. "Social adaptation as a social process in the adaptation of military personnel". Pp. 1956-1966 in 13th EBES Conference. IstanbulAt: Istanbul.

Terziev, Venelin, and Sevdalina Dimitrova. 2014a. "A New Approach to Social Adaptation of Decommissioned Servicemen and Their Families". Pp. 12-14 in The 20th International Conference, The Knowledge-Based Organization, Economic, Social and Administrative Approaches to the KnowledgeBased Organization. https://doi.org/10.2139/ssrn.3013262

Terziev, Venelin. 2016. "Personnel management systems in the field of security and defense: social policy for social activities". Eurasian Union of Scientists 12:84-90.

Terziev, Venelin. 2018. "Opportunities of application of a competence-based approach in social adaptation of militaries discharged of service". International E-Journal of Advances in Social Sciences 4:1-11. https://doi.org/10.2139/ssrn.3142919

Treadwell, James. 2016. "The Forces in the Firing Line? Social Policy and the 'Acceptable Face' of Violent Criminality". In The Palgrave handbook of criminology and war, eds. Ross McGarry and Sandra Walklate, 331-346. London: Palgrave Macmillan, 2016. https://doi.org/10.1057/978-1-137-43170-7_18

Tsindeliani, Imeda. 2019. "Public Financial Law in Digital Economy". Informatologia 52(3-4): 185-193. https://doi.org/10.32914/i.52.3-4.6

Walker, David I. 2013. "Anticipating army exit: identity constructions of final year UK career soldiers". Armed Forces \& Society 39:284-304. https://doi.org/10.1177/0095327X12437689

Wilmoth, Janet M., Andrew S. London, and Wendy M. Parker. 2011. "Sex differences in the relationship between military service status and functional limitations and disabilities". Population Research and Policy Review 30:333-354. https://doi.org/10.1007/s11113-010-9191-0

Zorictueva, Anastasia. 2010. State policy towards war veterans in Russia and Germany. "Bulletin of the East Siberian State Technological University" 4:158-161.

DOI: https://doi.org/10.6000/1929-4409.2020.09.144

(C) 2020 Inshyn et al.; Licensee Lifescience Global.

This is an open access article licensed under the terms of the Creative Commons Attribution Non-Commercial License (http://creativecommons.org/licenses/by-nc/3.0/) which permits unrestricted, non-commercial use, distribution and reproduction in any medium, provided the work is properly cited. 